\title{
A Quantitative Analysis of the Interactions of Antipneumococcal Antibody and Complement
}

\section{in Experimental Pneumococcal Bacteremia}

\author{
Eric J. Brown, Stephen W. Hosea, Carl H. Hammer, Cynthia G. Burch, and \\ Michael M. Frank, Laboratory of Clinical Investigation, National Institute \\ of Allergy and Infectious Diseases, National Institutes of Health, \\ Bethesda, Maryland 20205
}

\begin{abstract}
A B S TRACT The mechanism of protection of typespecific antipneumococcal antibody and complement in bacteremia was investigated with purified rabbit antibody and a guinea pig model of pneumococcal bacteremia. IgG and IgM were isolated from the sera of rabbits immunized with type 7 pneumococci $(\mathrm{Pn})$, and their binding to Pn was quantitated. The number of antibody-binding sites on the pneumococcal capsule was also determined. Pn were incubated with various amounts of the immunoglobulin preparations before intravenous injection into nonimmune guinea pigs. Whereas 120 molecules of IgM per Pn were sufficient to enhance bloodstream clearance of $\mathrm{Pn}, 1,400$ molecules of IgG per bacterium were required to produce this effect. As the amount of either IgG or IgM added to the Pn was increased, the rate of bloodstream clearance accelerated. In striking contrast, $>1,000$ molecules of IgM had no effect on the rate of clearance in C4-deficient guinea pigs, which cannot activate complement via the classic pathway. Similarly, 5,000 molecules of IgG had only minimal effect in C4-deficient guinea pigs, and 24,000 molecules of IgG had no effect in guinea pigs depleted of complement by cobra venom factor. Thus, the in vivo opsonic effects of both IgG and IgM anticapsular antibody are mediated via their ability to activate complement.
\end{abstract}

IgG anti-pneumococcal cell wall antibody, raised by intravenous injection of rabbits with unencapsulated Pn, had no effect on the rate of bloodstream clearance

This work was presented in part at the 20th Interscience Conference on Antimicrobial Agents and Chemotherapy, New Orleans, Louisiana, 22-24 September 1980, and in part at the National Meeting of the Association of American Physicians, American Society for Clinical Investigation, and American Federation for Clinical Research, San Francisco, California, 25-27 April 1981.

Received for publication 28 April 1981 and in revised form 17 August 1981. of Pn or on the polymorphonuclear leukocyte killing of type $7 \mathrm{Pn}$ in an in vitro bacterial assay. Because the opsonic effects of anticapsular antibody required complement activation, the ability of anticell wall IgG to activate complement was compared with the two classes of anticapsular antibody. As judged by depletion of C3 and C4 from guinea pig serum, as well as by the fixation of radiolabeled C3 to Pn, IgM anticapsular antibody was the best complement activator. However, anticell wall IgG was somewhat more active than anticapsular IgG in each of these tests of complement activation and fixation. When equivalent amounts of C3 were fixed to Pn by each of the three antibodies, Pn sensitized with IgG and IgM anticapsular antibodies caused immune adherence, whereas Pn sensitized with anticell wall IgG did not. This may explain the failure of anticell wall antibody to mediate complement-dependent phagocytosis of $\mathrm{Pn}$ in vivo or in vitro. Although anticell wall IgG is capable of activating complement and fixing C3 to Pn, it is not opsonic; the most likely reason is that the nonopsonic antibody mediates C3 deposition in sites on the Pn that cannot interact efficiently with phagocytic cell C3 receptors.

\section{INTRODUCTION}

In 1897 Bezançon and Griffon (1) recognized serologic differences among pneumococci $(P n)^{1}$ which later

\footnotetext{
${ }^{1}$ Abbreviations used in this paper: CFU, colony-forming unit; CVF-GP, cobra venom factor-treated guinea pig; C4DGP, C4-deficient guinea pig; E, erythrocytes; GPE, guinea pig erythrocytes; GPS, guinea pig serum; GVBD, $0.060 \mu \mathrm{M}$ isotonic dextrose veronal-buffered saline containing $1.0 \mathrm{mM}$ $\mathrm{Mg}$ and $0.15 \mathrm{mM} \mathrm{Ca}^{++}$; HBSS, Hanks' buffered salt solution; IEP, immunoelectrophoresis; NIH-GP, National Institutes of Health (normal) guinea pigs; PBS, phosphate-buffered saline; PMN, polymorphonuclear leukocytes; Pn, pneumococci; RES, reticuloendothelial system.
} 
were correlated with differences in the specific soluble substance, or polysaccharide capsule, by Avery and Heidelberger (2). These differences assumed major clinical significance when it was recognized that infection with one type of Pn did not necessarily confer protection against infection by other pneumococcal types and, in the era of serum therapy, that only serum that contained antibody directed against the type-specific polysaccharide of the infecting organism was of therapeutic benefit $(3,4)$. It was also recognized at that time that antibodies could be induced by injection of rabbits with unencapsulated Pn or with pneumococcal cell wall lysates that reacted with the cell walls of all types of Pn $(5,6)$. With few exceptions $(6,7)$ the evidence from experimental systems using animal models of pneumococcal disease has been that this antibody plays at most a small role in resistance to infection by encapsulated organisms (8). The reasons for these important differences in efficacy between type-specific anticapsular antibody, which were easily shown to be opsonic (9) and these broadly reactive antibodies have not been carefully explored. For example, most studies of the biologic effects of antipneumococcal antibody $(10,11)$ were done before different antibody classes were distinguished, before the mechanisms of interaction of antibodies with complement were understood, and before the ability of Pn to activate complement without the mediation of antibody, via the alternative pathway, was discovered. More recent studies of the requirements for phagocytosis have often investigated particles other than Pn and have differed as to whether complement alone or antibody alone is a sufficient signal for phagocytosis $(12,13)$.

We have developed an in vivo model for the study of phagocytosis of Pn by the fixed macrophages of the reticuloendothelial system (RES) $(14,15)$. Previous data accumulated with this model, which employs the intravenous injection of Pn into guinea pigs, suggested that the protective effect of immunization requires the mediation of complement. These studies, however, lacked a precise quantitative analysis of the interaction among Pn, antibody, and complement. In this paper we extend our previous work by using purified rabbit antipneumococcal antibodies to analyze the importance of antibody class, antibody-complement interactions, and the cellular location of antibody and complement molecules in host defense against pneumococcal bacteremia.

\section{METHODS}

Buffers. The following buffers were prepared as previously described (16): veronal-buffered saline; veronal-buffered saline made $0.1 \%$ in gelatin and brought to $0.15 \mathrm{mM}$ $\mathrm{CaCl}_{2}$ and $1.0 \mathrm{mM} \mathrm{MgCl}_{2}$; veronal-buffered saline with $0.1 \%$ gelatin and $10 \mathrm{mM}$ ethylenediaminetetraacetate; $0.060 \mu \mathrm{M}$ isotonic dextrose veronal-buffered saline containing $1.0 \mathrm{mM}$
$\mathrm{Mg}^{++}$and $0.15 \mathrm{mM} \mathrm{Ca}^{++}$(GVBD). Phosphate-buffered saline (PBS), pH 7.4; and Hanks' buffered salt solution (HBSS) were obtained from the Media Unit, National Institutes of Health, Bethesda, Md.

Bacteria. Rough (R36a, ATCC no. 27336) and type 7 Pn (ATCC no. 6307) were obtained in lyophilized form (American Type Culture Collection, Rockville, Md.) and reconstituted in trypticase soy broth containing 5\% defibrinated sheep's blood. They were maintained on trypticase soy agar plates containing 5\% sheep's blood, and type $7 \mathrm{Pn}$ were passed in white mice monthly to maintain virulence. Staphylococcus aureus, Haemophilus influenzae, and Bacillus subtilis were obtained from the Clinical Microbiology Service, National Institutes of Health. For in vitro studies, organisms were heat killed by incubation at $56^{\circ} \mathrm{C}$ for $30 \mathrm{~min}$. This has been determined to be the lowest temperature and shortest time that reliably inactivate pneumococcal autolysin (17).

${ }^{75} \mathrm{Se}-\mathrm{Pn}$. Log-phase Pn were radiolabeled in a completely defined artificial medium (18) that contained $\left[{ }^{75}\right.$ Se]methionine (Amersham Ltd; Arlington Heights, Ill.) as the only source of methionine, as previously described (15). In brief, 2-h cultures of Pn were grown for $90 \mathrm{~min}$ in $40 \mathrm{ml}$ of the medium containing $40 \mu \mathrm{Ci}$ of $\left[{ }^{75} \mathrm{Se}\right.$ emethionine, washed twice in icecold PBS, pH 7.4, and used within $1 \mathrm{~h}$.

Guinea pigs. Normal (National Institutes of Health; NIHGP) or C4-deficient (C4D-GP) (19) $300-400 \mathrm{~g}$ female guinea pigs were obtained from colonies maintained by the National Institutes of Health. Blood was obtained from guinea pigs via cardiac puncture and was separated after $1 \mathrm{~h}$ at room temperature. The serum was stored in aliquots at $-70^{\circ} \mathrm{C}$ until used. This nonimmune serum had no detectable antitype 7 antibody as determined by enzyme-linked immunoabsorbent assay, performed as previously described (20).

In vivo complement depletion. Cobra venom factor, partially purified venom of Naja naja (Cordis Laboratories Inc., Miami, Fla.), was used to deplete alternative- and late-pathway-complement components by intravenous injection into guinea pigs as previously described (14). With this regimen, hemolytic C3 titers in these guinea pigs, as measured by standard methods, were $0.1-1 \%$ of normal at the time of induction of bacteremia (Cobra venom-treated guinea pigs; CVF-GP).

Antipneumococcal antibody. Rabbits were immunized with heat-killed formalinized Pn, either type 7 or R36a, according to the schedule of the Massachusetts Antitoxin and Vaccine Laboratory, Boston, Mass. (21). 4-10 wk after the beginning of immunization the production of antibody was assessed by the ability of dilutions of rabbit serum to agglutinate homologous Pn. Sera with the highest titers were selected for further purification. Rabbit sera were not pooled for purification. 15-25 ml of rabbit serum was mixed with saturated ammonium sulfate in the cold to give a final concentration of $30 \%\left(\mathrm{NH}_{4}\right)_{2} \mathrm{SO}_{4}$. The precipitate was resuspended in a minimal volume of PBS, $\mathrm{pH} 7.4$, and applied to a $1,500-\mathrm{ml}$ bed volume Biogel A $0.5-\mathrm{m}$ column (Bio-Rad Laboratories, Richmond, Calif.). The resultant peaks were then collected, concentrated, and sedimented in a $10-30 \%$ sucrose gradient for $16 \mathrm{~h}$ at $100,000 \mathrm{~g}$ (SW-4l rotor, Beckman Instruments Inc., Spinco Div., Irvine, Calif.). These highly purified IgG and IgM fractions were then stored at $4^{\circ} \mathrm{C}$ until used. Aliquots of these IgG and IgM pools were radiolabeled with ${ }^{125}$ I by the Bolton-Hunter reagent as previously described (22). This technique gave a final specific activity of $\sim 10^{5} \mathrm{cpm} / \mu \mathrm{g}$ IgG or IgM.

Immunoelectrophoresis. Immunoelectrophoresis (IEP) was performed with $0.9 \%$ agarose in veronal acetate buffer, $\mathrm{pH} 8.2$, at $30-\mathrm{V}$ potential across the IEP plate. Antisera used 
included goat antirabbit colostrum (kindly provided by Dr. Rose Mage, Laboratory of Immunology, National Institute of Allergy and Infectious Diseases, National Institutes of Health) and commercial antirabbit IgG, antirabbit IgA, antirabbit IgM, and antiwhole rabbit serum (Cappel Laboratories, Cochranville, Pa., and Miles-Yeda, Ltd. Elkhart, Ind.). Ouchterlony double diffusion was also performed to test the IgG and IgM pools against the monospecific antisera.

Binding of ${ }^{125}$ I-antibody to $P n$. [ $\left.{ }^{125} \mathrm{I}\right] \mathrm{IgG}$ or IgM was diluted 1:100 in PBS and incubated with various numbers of type $7 \mathrm{Pn}$, rough $\mathrm{Pn}, B$. subtilis, $H$. influenzae, or Staphylococcus aureus in a total volume of $1 \mathrm{ml}$ for $30 \mathrm{~min}$ at room temperature. Preliminary studies had shown these time and temperature conditions to be sufficient for reaching equilibrium. The suspension of bacteria and IgG was then passed through a $0.45-\mu \mathrm{m}$ Millipore filter (Millipore Corp., Bedford, Mass.) precoated with bovine serum albumin (Sigma Chemical Co., St. Louis, Mo.) via gentle vacuum suction. The filter was washed extensively with PBS, pH 7.4, and the filterassociated radioactivity was determined. Radioactivity bound to unrelated organisms was considered nonspecific background radioactivity. In this way, a maximum percentage of each pool that would bind specifically to type 7 or rough Pn could be determined. Pneumococcal cell walls contain the Forssman antigen (23). Therefore, in the case of IgG antibody prepared against rough Pn (anticell wall IgG), binding to Forssman antigen-positive and Forssman antigennegative erythrocytes (E) was also determined. For determination of binding of radiolabel to these $E$, the cells were pelleted after incubation through a solution of $25 \%$ albumin in PBS at $12,000 \mathrm{~g}$ (Eppendorf table-top centrifuge, Brinkmann Instruments, Inc., Westbury, N. Y.) in 1.5-ml plastic tubes (Brinkmann Instruments). The supernatants were then removed, the tubes were cut, and radioactivity associated with the portions of the tubes containing the cell pellets was determined (Gamma 310 system, Beckman Instruments).

Determination of IgG binding sites. Studies of IgG binding sites were performed as described for the determination of antibody binding except that the number of type 7 Pn was held constant and the amount of $\left.{ }^{125} \mathrm{I}\right] \mathrm{IgG}$ offered was varied. In this way, the maximum number of IgG molecules which would bind to a predetermined number of type $7 \mathrm{Pn}$ could be determined. Controls for these experiments included determination of binding to unrelated organisms, as described above, and to type $7 \mathrm{Pn}$ in the presence of a 20 fold excess of unlabeled IgG. These binding studies were performed with $10^{6}, 5 \times 10^{6}$, and $10 \times 10^{6}$ colony-forming units (CFU) of type $7 \mathrm{Pn}$.

Protein A adsorption. In some studies we depleted the IgG pool of IgG antibody by adsorption to staphylococcal protein A. $54.8 \mathrm{mg}$ of protein-A Sepharose (Pharmacia Fine Chemicals, Piscataway, N. J.) was suspended in $1 \mathrm{ml}$ of PBS. After swelling, the Sepharose beads were centrifuged, the supernatant was discarded, and $275 \mu \mathrm{g}{ }^{125} \mathrm{I}$-labeled IgG in $1 \mathrm{ml}$ PBS was added to the Sepharose beads. The mixture was incubated with frequent shaking for $1 \mathrm{~h}$ at $37^{\circ} \mathrm{C}$. The beads were removed by centrifugation and discarded. The supernatant material was then compared with unadsorbed material on IEP and in its ability to bind to type $7 \mathrm{Pn}$, as described above.

Clearance studies. $10^{8}$ live type 7 Pn from 2-h broth cultures were washed twice with PBS and then sensitized by incubation with various dilutions of unlabeled antibody in PBS or with PBS alone for $30 \mathrm{~min}$ at room temperature. Thereafter, the sensitized Pn were kept on ice until injection, always within $30 \mathrm{~min}$. Quantitative cultures of these suspensions were made before and after these incubations to ensure that there was no toxic effect of the antibody solution and that the room temperature incubation did not lead to a nonspecific loss of viability. There was no difference in colony counts between Pn suspensions before and after incubation or between those incubated with antibody and with PBS alone. The rate of removal of these sensitized Pn from the bloodstream of guinea pigs after intravenous injection was determined by serial bleeding from the retroorbital plexus at prescribed times after injection, as previously described $(14,20)$. Clearance studies were performed with two or three animals at each level of antibody sensitization. An equal number of control animals received unsensitized Pn in each experiment.

Localization in NIH-GP. Studies of localization of NIHGP were performed as previously described (20) by killing guinea pigs $45 \mathrm{~min}$ after the injection of $10^{8}-10^{9}{ }^{75} \mathrm{Se}-\mathrm{Pn}$, preincubated with antibody diluted in PBS or with PBS alone as a control. Whole-organ radioactivity counts were made of liver, spleen, and lung. An aliquot $(0.2 \mathrm{ml})$ of whole blood was also counted (Gamma 310 Radiation Counter, Beckman Instruments), and the radioactivity remaining in blood was calculated by assuming a blood volume equal to $7 \%$ of the body weight. This figure had been determined from the injection of ${ }^{51} \mathrm{Cr}$-labeled, unsensitized guinea pig E. Detailed studies of bloodstream clearance and localization kinetics have been reported $(20,21)$. In brief, there is an early exponential removal of $\mathrm{Pn}$ from the blood that continues for 2-4 $\mathrm{h}$. In the first $5 \mathrm{~min}$ after injection as many as $25 \%$ of the Pn are localized in the pulmonary circulation, but this phase of clearance is over by $30 \mathrm{~min}$. Thus, for the localization experiments reported here, $45 \mathrm{~min}$ was chosen as a time at which log-phase clearance was still progressing, dilution of radiolabel by division of microorganisms was minimal, and the radiolabeled organisms had not been destroyed and released from the RES by phagocytic cell lysosomal activity. Preliminary studies showed that the relative ratio of hepatic to splenic sequestration is maintained throughout the exponential phase of clearance.

Bactericidal assay. Type 7 Pn from a 4-h broth culture were washed two times in HBSS and resuspended to $1 \times 10^{8} /$ $\mathrm{ml}$ in HBSS. Polymorphonuclear leukocytes (PMN) were obtained from peripheral blood by dextran sedimentation and Hypaque-Ficoll density gradient centrifugation as previously described (24). $1 \mathrm{ml}$ of a reaction mixture was made that contained $1 \times 10^{7} \mathrm{Pn}, 0.1 \mathrm{ml}$ fresh normal human serum that had low titers of antibody to type 7 polysaccharide determined by enzyme-linked immunoabsorbent assay as previously described (25), $1 \times 10^{7} \mathrm{PMN}$, and purified rabbit antibody in amounts calculated to sensitize each Pn with between 100 and 1,000 antibody molecules/CFU of IgG antitype 7, IgM antitype 7, or IgG anticell wall antibody. To control tubes were added Pn, serum, and PMN, but PBS was substituted for antibody. The tubes were incubated at $37^{\circ} \mathrm{C}$ for $60 \mathrm{~min}$, and viable bacteria were quantitated at 0,30 , and 60 min by quantitative colony counts of serial dilutions of the incubation mixture in cold PBS.

Purification of guinea pig C3. Guinea pig C3 was purified by a modification of the method of Hammer et al. (26) developed for human complement components. In brief, plasminogen was removed from the supernatant of a $5 \%$ polyethylene glycol 4,000 (J. T. Baker Chemical Co., Phillipsburg, N. J.) precipitation of $400 \mathrm{ml}$ of freshly drawn guinea pig EDTA-plasma by passage over a lysine-Sepharose column. The polyethylene glycol 4,000 concentration was increased to $20 \%$, and the resulting precipitate was resuspended in a $0.032 \mathrm{M} \mathrm{NaCl}, 0.01 \mathrm{M}$ EDTA, $0.005 \mathrm{M}$ phosphate buffer $\left(3.2 \mathrm{mS}\right.$ at $\left.0^{\circ} \mathrm{C}\right)$ and applied to a $2.5 \times 195$-cm DEAE 
Sephacel column (Pharmacia Fine Chemicals). The C3 peak, as determined by hemolytic titration, was pooled, concentrated by a second $20 \%$ polyethylene glycol 4,000 precipitation, resuspended in a $0.15 \mathrm{M} \mathrm{NaCl}, 0.05 \mathrm{M}$ phosphate, $0.01 \mathrm{M}$ EDTA buffer, and applied to a column of Sepharose 6B-CL (Pharmacia Fine Chemicals). In a final step, trace contaminants in the $\mathrm{C} 3$ pool were removed by passage over an immunoabsorbent column. The antibody for this immunoabsorbent was prepared by immunization of a goat with the supernatant of an octanoic acid (Eastman Kodak Co., Rochester, N. Y.) precipitation (27) of guinea pig serum (GPS). The IgG fraction of this goat antiserum was prepared by octanoic acid precipitation and coupled to Sepharose 4B via cyanogen bromide (28). The resultant $\mathrm{C} 3$ showed a single band on sodium dodecyl sulfate-polyacrylamide gel electrophoresis (29). When the C3 was reduced with $1 \% 2$-mercaptoethanol and analyzed by sodium dodecyl sulfate-polyacrylamide gel electrophoresis, an $\alpha$-chain of 108,000 daltons and a $\beta$-chain of 64,000 daltons were seen. IEP vs. anti-whole GPS (Hyland Laboratories, Los Angeles, Calif.) showed only a single precipitin, and antibody raised against this preparation in goats showed only a single precipitin on IEP vs. whole GPS. Aliquots of the C3 were radiolabeled with ${ }^{125}$ I by the Bolton-Hunter reagent. There was no loss of C3 hemolytic activity on radiolabeling.

Complement depletion studies. $5 \times 10^{7}$ heat-killed Pn were preincubated with enough antibody diluted in PBS to supply 1,000-10,000 molecules of IgM per bacterium and 5,000-50,000 molecules of IgG per bacterium. They were washed once in PBS and resuspended in $250 \mu \mathrm{l}$ of pooled nonimmune GPS diluted $1: 100$ in veronal-buffered saline made $0.1 \%$ in gelatin and brought to $0.15 \mathrm{mM} \mathrm{CaCl}_{2}$ and $1.0 \mathrm{mM} \mathrm{MgCl}$. $1 \%$ GPS was chosen because it allowed the reliable detection of increased C3 depletion by antibodysensitized Pn as compared with unsensitized Pn. Presumably this occurred because antibody-mediated classic pathway activation is less inhibited by dilution of serum than is direct activation of the alternative pathway by the Pn. After the antibody-coated Pn were incubated in dilute GPS for $1 \mathrm{~h}$ at $37^{\circ} \mathrm{C}$, the bacteria were pelleted, and the supernatant was assayed for $\mathrm{C} 3$ and $\mathrm{C} 4$ by a standard hemolytic titration procedure (30). The C3 or C4 depletion in each of these sera was calculated by comparing the postincubation hemolytic titers to the C3 and C4 titers of sera incubated with type 7 Pn that had been preincubated in PBS rather than antibody. All depletion studies were performed in duplicate at each level of antibody sensitization, and each experiment was performed at least twice.

${ }^{125}$ I-C3 uptake onto Pn. $5 \times 10^{7}$ type 7 Pn were sensitized with IgG or IgM antibody as described above, washed, and resuspended in $250 \mu$ l of GPS diluted 1:100 in veronal-buffered saline made $0.1 \%$ in gelatin and brought to $0.15 \mathrm{mM}$ $\mathrm{CaCl}_{2}$ and $1.0 \mathrm{mM} \mathrm{MgCl}{ }_{2}$ and containing $5 \mu \mathrm{l}(1.7 \mu \mathrm{g})$ of ${ }^{125} \mathrm{I}-\mathrm{C} 3$. After incubation for $30 \mathrm{~min}$ at $37^{\circ} \mathrm{C}$, previously determined to be the time of maximum $\mathrm{C} 3$ binding, the serum-incubated Pn were collected on a $0.45-\mu \mathrm{m}$ Millipore filter precoated with albumin via gentle vacuum suction and washed extensively with PBS. The filter-associated radioactivity was then determined. C3 uptake at each antibody input was assessed in duplicate. Controls included incubation of unsensitized (PBS-incubated) Pn under similar conditions and incubation of identically sensitized Pn in GPS diluted in veronal-buffered saline with $0.01 \%$ gelatin and $10 \mathrm{mM}$ EDTA. In all cases, the filter-associated radioactivity of control tubes was $<4 \%$ of ${ }^{125}$ I input.

To examine the ability of the IgG and IgM antibodies to support the assembly of a classic-pathway C3 convertase from purified guinea pig complement components, the following studies were carried out. $5 \times 10^{7}$ type 7 Pn sensitized as described above were washed, resuspended in $0.5 \mathrm{ml}$ GVBD, incubated with $1,000 \mathrm{U}$ of $\mathrm{Cl}$ (Cordis Laboratories) for $15 \mathrm{~min}$ at $30^{\circ} \mathrm{C}$, washed in GVBD at room temperature, and resuspended in GVBD as described above. These Pn were then incubated with $100 \mathrm{U}$ of $\mathrm{C4}$ (Cordis Laboratories) for $30 \mathrm{~min}$ at $37^{\circ} \mathrm{C}$, washed in GVBD at $4^{\circ} \mathrm{C}$, and finally resuspended in GVBD. $100 \mathrm{U}$ C2 (Cordis Laboratories) was then added to these Pn. The mixture was incubated for 10 min at $30^{\circ} \mathrm{C}$, and $3.5 \mu \mathrm{g}{ }^{125} \mathrm{I}-\mathrm{C} 3$ was then added. The bacteria were then incubated with the complement components for $\mathrm{l} \mathrm{h}$ at $37^{\circ} \mathrm{C}$ and washed on albumin-coated Millipore filters as described above. All experiments were performed on at least two occasions and in duplicate on each occasion. Controls included determination of C3 uptake on unsensitized Pn and antibody-sensitized Pn that had been incubated with GVBD instead of $\mathrm{Cl}$ or C2. Uptake in control tubes in these experiments was always $<1.5 \%$ of $\mathrm{C} 3$ input.

Immune adherence. $5 \times 10^{7} \mathrm{Pn}$ were sensitized with 5,000 molecules/CFU of IgG anti-type 7, 5,000 molecules of IgG anti-cell wall, or 1,000 molecules/CFU of IgM antitype 7. Pn were then incubated as described above with purified $\mathrm{Cl}, \mathrm{C4}, \mathrm{C} 2$, and C3. The number of C3b molecules/ CFU was determined from the net uptake of radiolabeled C3. $1.5 \times 10^{7}$ of such antibody- and complement-sensitized Pn, suspended in $40 \mu \mathrm{l} \mathrm{GVBD,} \mathrm{were} \mathrm{incubated} \mathrm{in} \mathrm{microtiter}$ plates with $25 \mu \mathrm{l}$ of washed fresh human type $\mathrm{O}, \mathrm{Rh}$ positive E suspended to $6.5 \times 10^{7} \mathrm{E} / \mathrm{ml}$ in GVBD. These suspensions were incubated at $37^{\circ} \mathrm{C}$ for $15 \mathrm{~min}$, and agglutination patterns were quantitated as previously described (16).

Statistical methods. Hepatic and splenic localization data and geometric means of blood colony counts were compared by a two-tailed Student's $t$ test. Data are expressed as mean \pm SEM.

\section{RESULTS}

Binding of anticapsular IgG and IgM to Pn. A maximum of $3.5 \%$ of the radiolabeled IgG preparation bound to type $7 \mathrm{Pn}$. $1 \%$ of this antibody preparation bound to rough $\mathrm{Pn}$, and negligible amounts $(<0.1 \%)$ bound to unrelated organisms (Fig. 1). Three antibody preparations, made from three different immune sera, all showed maximum binding of $3.0-3.5 \%$ to type 7 Pn. When the antibody preparations were first absorbed with $10^{9}$ rough $\mathrm{Pn}$, binding to rough $\mathrm{Pn}$ was abolished but binding to type $7 \mathrm{Pn}$ was unchanged. Thus, virtually all of the $3.5 \%$ of the IgG that bound to the type $7 \mathrm{Pn}$ was directed to unique type 7 antigens. Previous work has shown that virtually all of this antibody is directed against the capsular polysaccharide (31). In confirmation, binding in our assay of ${ }^{125} \mathrm{I}-\mathrm{IgG}$ to type $7 \mathrm{Pn}$ was completely ablated by the addition of purified type 7 polysaccharide to the IgG pool. Three separate IgM pools contained between 10 and $12 \%$ specific anti-type $7 \operatorname{IgM}$ (Fig. 2). There was very little specific binding of the $\operatorname{IgM}$ pool to rough $\mathrm{Pn}$, always $<10 \%$ of the binding to encapsulated type 7 $\mathrm{Pn}$. When the IgM pool was absorbed with $10^{9}$ rough $\mathrm{Pn}$, binding to rough $\mathrm{Pn}$ was abolished but binding to type 7 Pn was left unchanged, just as with the purified 
IgG. From this information the exact number of anticapsular antibody molecules present in any volume of the IgG or IgM pool could be calculated by knowing the quantity of total protein present, as determined by the absorbance at $280 \mathrm{~nm}$.

Calculation of the contribution of IgA to specific binding. The IgM pool as purified contained no detectable IgG or IgA as judged by IEP against antirabbit colostrum, antiwhole rabbit serum, antirabbit IgG, or antirabbit IgA or double diffusion against the monospecific anti-IgG and anti-IgA. On IEP and double diffusion the IgG preparation showed no contamination with IgM, but both antirabbit colostrum and anti-whole rabbit serum showed that IgA was present. Unfortunately, because neither commercial monospecific antirabbit IgA antiserum tested reacted with the preparation on IEP or by double diffusion, direct quantitation of the extent of IgA contamination was not possible. However, the specific antitype 7 IgA was quantitated by comparing the binding of ${ }^{125}$ I-labeled antibody before and after removal of IgG by protein $A$ adsorption. After protein $A$ adsorption, the IgG precipitin on IEP was completely abolished, but the IgA line remained present and its intensity was qualitatively unchanged. At the same time, the binding to type 7 Pn was almost entirely abolished. Direct comparison of the maximum binding of radiolabel before and after protein $A$ adsorption showed a reduction of specific binding by $97.3 \%$ after protein $A$ adsorption. Thus, $<5 \%$ of the specific antipneumococcal antibody in the IgG pool was IgA.

Calculation of IgG binding sites on the pneumococcal capsule. Inasmuch as the total number of anticapsular antibody molecules per microgram of the total IgG preparation was now known, calculation of the available antibody-binding sites was possible. Increasing amounts of radiolabeled antibody were added to $10^{6}, 5 \times 10^{6}$, or $10^{7} \mathrm{Pn}$, and the uptake of radiolabel was determined in the presence and absence of a 20 fold excess of unlabeled antibody. Binding to unrelated organisms was also used as a control for nonspecific uptake of radiolabel. Scatchard plots of this data led to a calculation of 150,000 binding sites/CFU (Fig. $3 A)$. By the use of Scatchard analysis, the total number of IgG binding sites present in the whole pneumococcal pool was determined at each of the three concentrations of organisms. When these numbers were plotted vs. the total number of organisms present, the slope of the line also indicated 150,000 IgG binding sites/ CFU (Fig. 3B). Thus, the theoretical maximum number of IgG anticapsular antibody molecules that would bind to a $\mathrm{Pn}$, as determined by two techniques, was 150,000 .

IgG anticell wall binding to Pn. Radiolabeled anticell wall IgG bound specifically to both rough Pn and

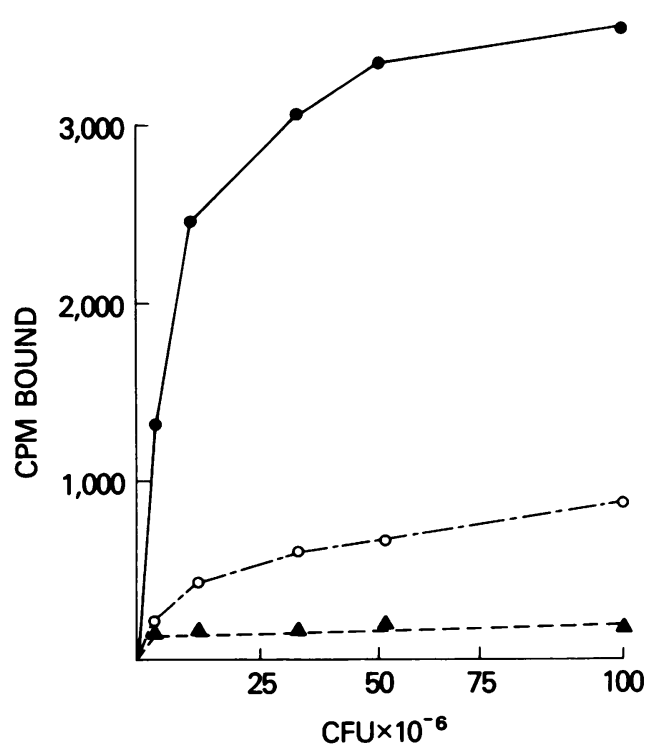

Figure 1 The binding of anticapsular IgG to bacteria. The binding of ${ }^{125} \mathrm{I}$-labeled rabbit antitype 7 IgG to increasing numbers of type $7 \mathrm{Pn}(0)$, unencapsulated $\mathrm{Pn}(O)$, and unrelated organisms $(\Delta)(H$. influenzae type b, B. subtilis, and Staphylococcus aureus) is shown. Input of radiolabeled IgG in all cases was $100,000 \mathrm{cpm}$.

type 7 Pn (Fig. 4). The maximum amount of the radiolabel that bound to rough Pn was greater than that bound to type 7 Pn (9.7 vs. $7.3 \%$ ), implying that there were antigens present on these rough Pn (derived from

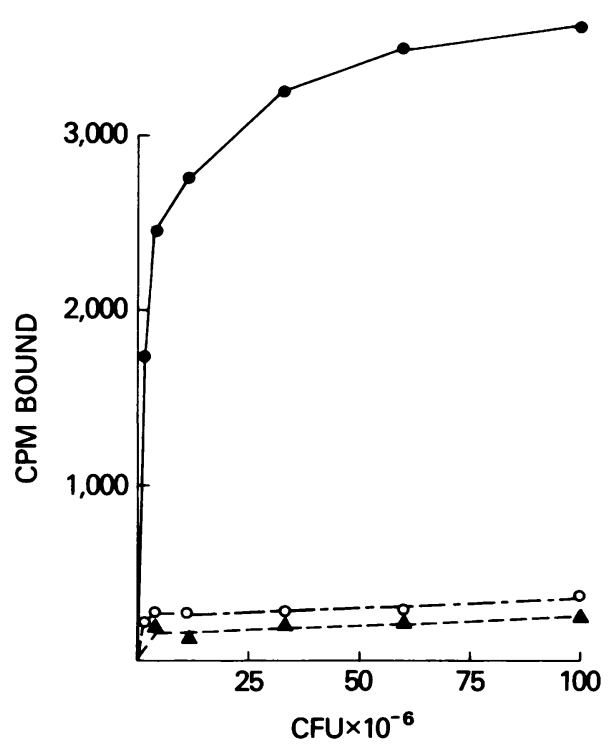

Figure 2 The binding of anticapsular IgM to bacteria. The binding of ${ }^{125} \mathrm{I}$-labeled rabbit antitype $7 \mathrm{IgM}$ to increasing numbers of type $7 \mathrm{Pn}(\bullet)$, unencapsulated Pn (O), and unrelated organisms $(\Delta)$ are compared. Input of radiolabeled IgM in all cases was $30,000 \mathrm{cpm}$.

Pneumococcal Antibody and Complement 
A

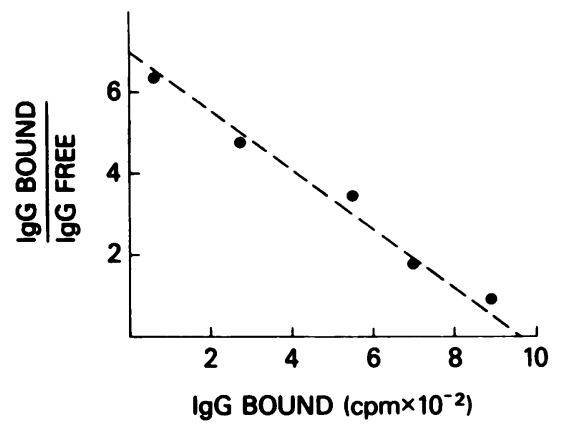

B

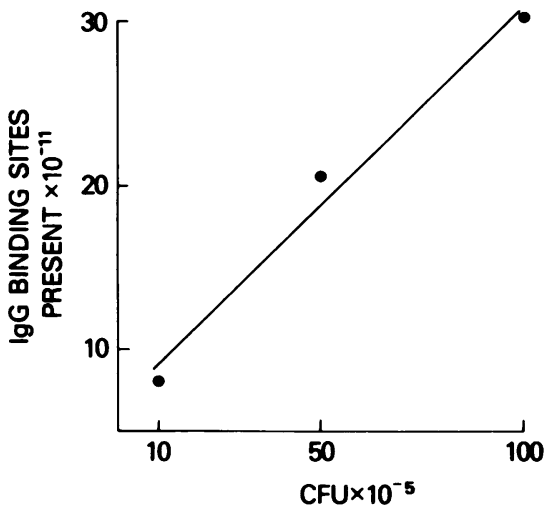

Figure 3 IgG-binding sites on type $7 \mathrm{Pn}$. In A, a Scatchard plot of IgG binding to $10^{6}$ type $7 \mathrm{Pn}$ is shown. The $x$ intercept of this line corresponds to $150,000 \mathrm{IgG}$ molecules bound/CFU. In $B$, the total number of IgG binding sites present, as determined by Scatchard analysis, is plotted vs. number of organisms. The slope of this line is 150,000 molecules/CFU.

a type 2 strain) that were either not present or not exposed on type $7 \mathrm{Pn}$. Less than $0.1 \%$ of the radiolabel bound to unrelated bacteria. Binding of the IgG to Forssman antigen-positive (sheep and guinea pig) and Forssman antigen-negative (human and rabbit) $\mathrm{E}$ was also determined. There was no difference in binding

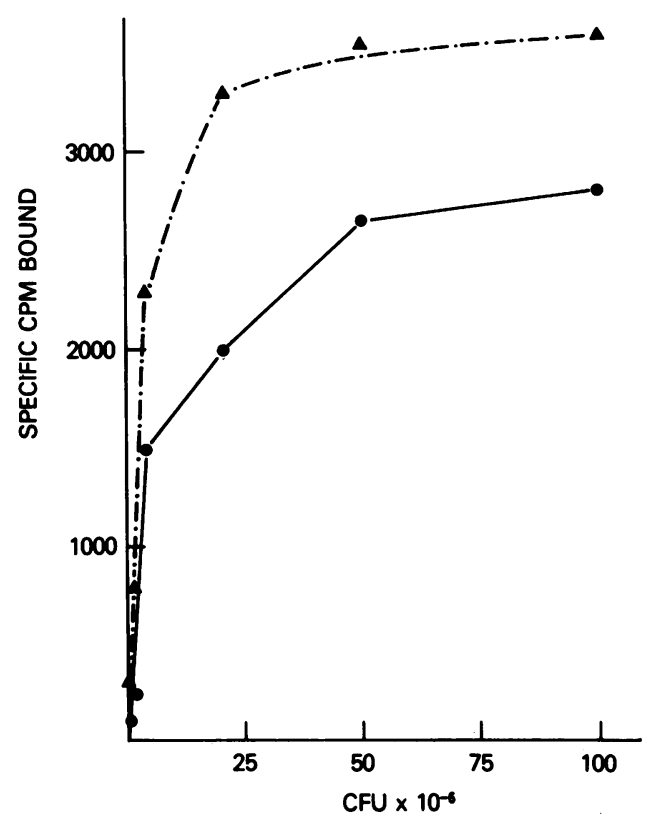

FIGURe 4 The binding of anticell wall IgG to Pn. The binding of ${ }^{125} \mathrm{I}$-labeled IgG anticell wall to increasing numbers of organisms is compared for type $7(\bullet)$ and rough $(\Delta) \mathrm{Pn}$. $40,000 \mathrm{cpm}{ }^{125} \mathrm{I}-\mathrm{IgG}$ was added to each reaction mixture, and the incubation was carried out at room temperature for $30 \mathrm{~min}$. of radiolabel to Forssman-positive and Forssman-negative $\mathrm{E}$ (all $<0.1 \%$ of radiolabeled IgG added), implying that the anticell wall antibody was not directed against the pneumococcal Forssman antigen.

Clearance of IgG-sensitized Pn in complementsufficient guinea pigs. The ability of the anticapsular IgG to opsonize type $7 \mathrm{Pn}$ for clearance from the bloodstream of NIH-GP was assessed by incubating known amounts of IgG with $10^{8} \log$-phase $\mathrm{Pn}$ and then injecting these opsonized Pn intravenously into guinea pigs. The number of molecules used was in all cases far less than the agglutinating dose of this IgG for type $7 \mathrm{Pn}$. Control animals received Pn preincubated in PBS. Fig. 5 shows the results of these experiments. Whereas 500 molecules of IgG had no effect on the rate of pneumococcal clearance, 1,400 molecules of IgG significantly increased the rate of clearance of these $P n$ from the bloodstream $(P<0.01$ at each time point) (Fig. 5). 3,500 IgG/CFU accelerated clearance even further $(P<0.01$ compared with 1,400 molecules of IgG); 10,000 molecules of IgG/CFU caused slightly but not significantly faster clearance of Pn than 3,500 molecules/CFU (data not shown).

Localization of Pn during pneumococcal bacteremia. We $(15,20)$ have shown that $60-70 \%$ of radiolabeled Pn can be recovered in the splanchnic RES of guinea pigs at $45 \mathrm{~min}$ after the induction of bacteremia and that hepatic sequestration predominates over splenic sequestration by 3-5:1 in nonimmune guinea pigs. In the present study, hepatic and splenic localization of radiolabeled $\mathrm{Pn}$ were compared in guinea pigs injected with Pn preincubated with no antibody; with 500 molecules IgG/CFU, a dose below the threshold of increased clearance; and with 3,000 molecules IgG/CFU, a dose that leads to rapid bloodstream clear- 


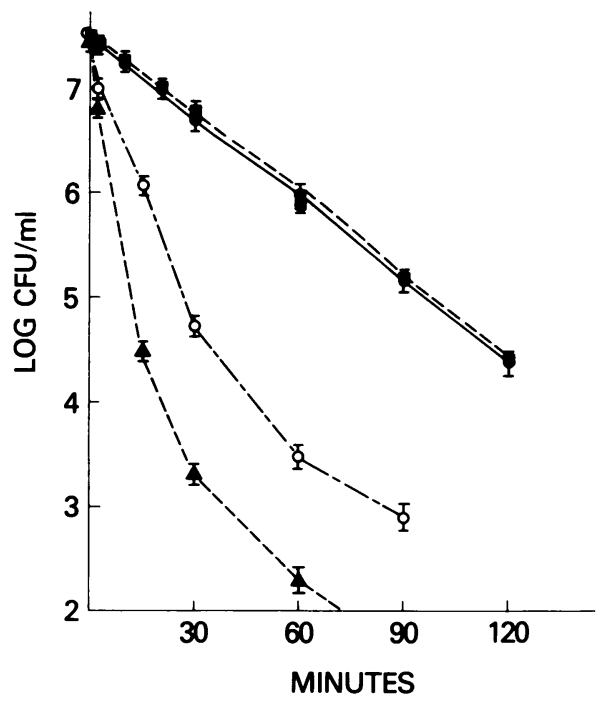

FIGURE 5 The clearance of IgG-sensitized type 7 Pn in NIHGP. The clearance of type 7 Pn sensitized with $0(0), 500$ $(\square), 1,400(O)$, and 3,500 ( $\Delta)$ molecules of IgG/CFU is compared by plotting CFU per milliliter of blood vs. the time since intravenous injection of the Pn.

ance (Table I). There was no difference between the sequestration patterns of unsensitized Pn and Pn sensitized with 500 molecules IgG/CFU. However, there was a significant increase in the hepatic sequestration of $\mathrm{Pn}$ incubated with enough antibody to give 3,000 IgG/CFU $(P<0.01)$. Splenic sequestration in these animals was less than that in animals injected with unsensitized Pn, but the difference did not reach statistical significance.
Clearance of IgG-sensitized Pn in C4D-GP and CVF-GP. The clearance of $P n$ sensitized with anticapsular IgG was compared with unsensitized Pn in C4D-GP, in which complement can be activated only via the alternative pathway. In these animals, 5,000 molecules of IgG/CFU, which causes nearly maximal clearance rates in NIH-GP, caused a slight, statistically significant increase in the rate of clearance (Fig. 6A). However, the rate of clearance of these Pn sensitized with 5,000 IgG/CFU in C4D-GP was not as fast as the rate of clearance of even unsensitized Pn in NIH-GP. In CVF-GP, which are depleted of alternative pathway components and C3-C9, Pn sensitized with 24,000 IgG molecules/CFU were cleared with kinetics no different from the clearance of unsensitized $P n$ in CVF-GP and markedly slower than the clearance of unsensitized Pn in NIH-GP (Fig. 6B).

Clearance of IgM-sensitized Pn. The kinetics of clearance of Pn preincubated with PBS or various amounts of IgM is shown in Fig. 7A. In complementsufficient NIH-GP as few as 120 molecules of IgM/ CFU caused a statistically significant increase in the rate of pneumococcal clearance. There was a dose-dependent increase in clearance rates as with IgG. 500 molecules/CFU caused nearly maximal clearance rates, since the rate of clearance of Pn sensitized with 5,000 molecules of IgM/CFU was not different from that of Pn sensitized with 500 molecules of IgM/CFU (data not shown). The ability of IgM to enhance pneumococcal clearance was entirely dependent on activation of the classic pathway of complement, as shown by clearance kinetics in C4D-GP. In these guinea pigs $>1,000$ molecules of IgM/CFU had no effect on clear-

TABLE I

\begin{tabular}{|c|c|c|c|c|}
\hline Antibody & $\begin{array}{l}\text { Hepatic }^{\bullet} \\
\text { sequestration }\end{array}$ & $\begin{array}{c}\text { Splenic } \\
\text { sequestration }\end{array}$ & Liver/spleen & $\begin{array}{l}\text { Total RES• } \\
\text { sequestration }\end{array}$ \\
\hline & $\%$ & $\%$ & & $\%$ \\
\hline $\begin{array}{l}\text { None } \\
\qquad(n=4)\end{array}$ & $49 \pm 2.0$ & $16 \pm 2.0$ & 3.06 & 65 \\
\hline $\begin{array}{c}500 \mathrm{IgG} / \mathrm{CFU} \\
(n=5)\end{array}$ & $51 \pm 3.0$ & $15 \pm 1.5$ & 3.40 & 66 \\
\hline $\begin{array}{c}3,000 \mathrm{IgG} / \mathrm{CFU} \\
(n=4)\end{array}$ & $58 \pm 1.5 \downarrow$ & $10 \pm 1.0$ & 5.80 & 68 \\
\hline $\begin{array}{c}300 \operatorname{IgM} / \mathrm{CFU} \\
(n=2)\end{array}$ & $60 \pm 1.0 \$$ & $9 \pm 0.5$ & 6.67 & 69 \\
\hline
\end{tabular}

- Expressed as percent injected counts per minute recovered in liver, spleen, or both 45 min after the injection of $\mathrm{Pn}$ radiolabeled with $\left[{ }^{75}\right.$ Se]methionine that had been preincubated either with a predetermined amount of anticapsular antibody or with PBS. $f P<0.01$ compared with unsensitized $P$. $\S P<0.05$ compared with unsensitized $P n$. 

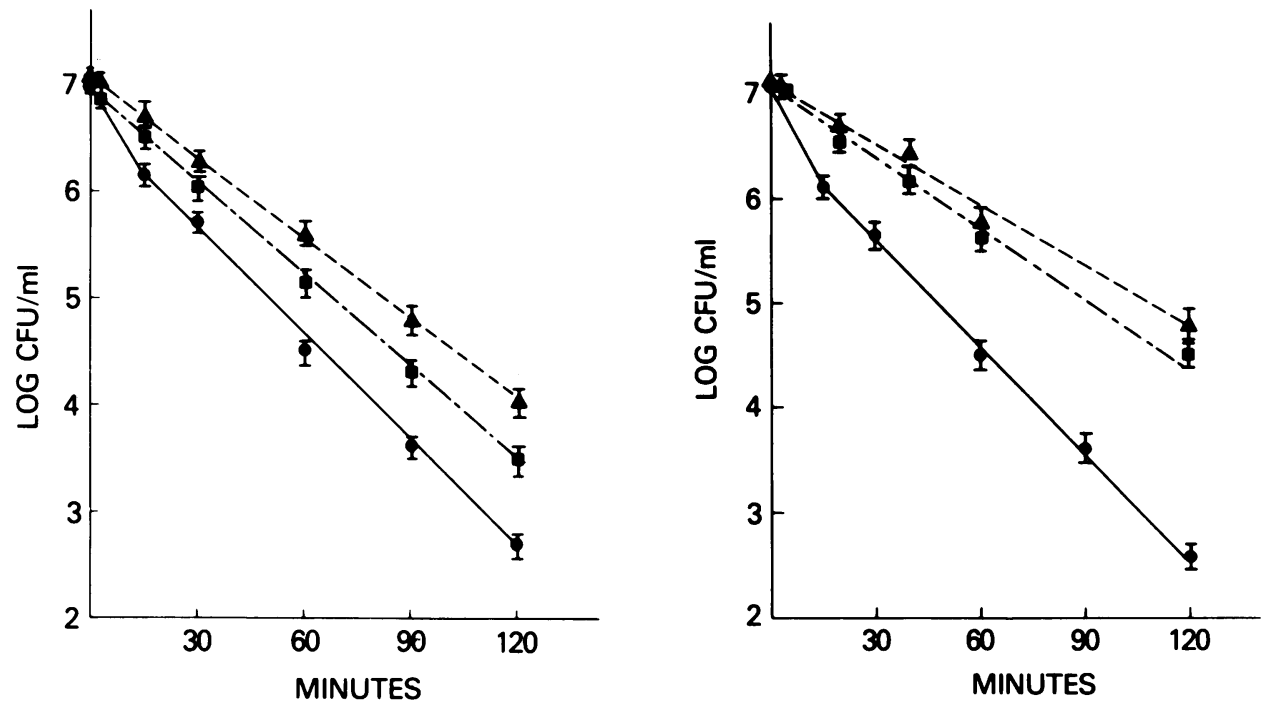

Figure 6 The clearance of IgG-sensitized Pn in C4D-GP and CVF-GP. A compares the clearance of type $7 \mathrm{Pn}$ sensitized with $0(\Delta)$ and 5,000 ( $(\mathbf{)})$ molecules of IgG/CFU by plotting CFU per milliliter of blood remaining at various times after intravenous injection. The clearance of unsensitized Pn in NIH-GP (O) is included for comparison. B compares the clearance of Pn sensitized with $0(\Delta)$ and $24,000(\square)$ molecules of IgG/CFU in CVF-GP. Again, the clearance of unsensitized Pn in NIH-GP (๑) is included for comparison.

ance rates (Fig. 7B). Localization studies performed with 300 molecules of IgM/CFU showed that IgM, like IgG, mediated increased hepatic sequestration of Pn (Table I).

Clearance studies with anticell wall antibody. Anticell wall IgG was incubated with type $7 \mathrm{Pn}$ to provide $1,600,3,200,15,000,30,000$, and 44,000 molecules of IgG/CFU. No dose of anticell wall antibody caused a change in the rate of pneumococcal clearance from the bloodstream, compared with Pn incubated with PBS alone (Fig. 8).

In vitro phagocytosis. The abilities of IgG anti-cell wall antibody and IgG and IgM anticapsular antibodies to enhance phagocytosis of pneumococci by human PMN were compared in an in vitro bactericidal assay. IgG and IgM anticapsular antibodies both were able to enhance complement-dependent pneumococcal killing by PMN in a dose-dependent fashion. However, anti-cell wall IgG had no effect on phagocytosis of pneumococci at any dose (Fig. 9). Because IgG and IgM anticapsular antibodies were able to enhance both bloodstream clearance of $\mathrm{Pn}$ in the guinea pig model and phagocytosis in vitro, they were considered opsonic antibodies. Because anticell wall IgG was active in neither of these assays, it was considered nonopsonic.

Antibody-mediated depletion of complement from serum. We next tested whether the difference be- tween the opsonic anticapsular antibodies and the nonopsonic anticell wall antibody lay in their ability to activate complement. For these experiments, Pn sensitized with various amounts of antibody were incubated with diluted GPS. The depletion of C4, a component of the classic pathway, was first examined. In nonimmune serum there was no detectable anticapsular antibody and no activation of the classic pathway was detectable without antibody sensitization. Hemolytic C4 titers of serum after incubation with unsensitized Pn were no different from the titers of serum to which Pn had not been added. Sensitizing the Pn with increasing amounts of antibody led to increasing C4 depletion (Fig. 10). Anticapsular IgM depleted C4 to the greatest extent. Surprisingly, IgG anticell wall antibody depleted $\mathrm{C} 4$ at least as well as anticapsular IgG in these experiments.

Next, the effect of the different antibody preparations on C3 depletion was examined. C3 can be activated via either the classic or the alternative pathway. Thus, a small amount of C3 depletion (10\%) was observed after incubation of unsensitized Pn in $1 \%$ nonimmune serum. This is consistent with direct activation of the alternative pathway by the unsensitized Pn. Sensitization of Pn with antibody led to dose-dependent increases in C3 depletion (Fig. 11). Again, IgM was most efficient at C3 activation. Anticell wall IgG depleted C3 to a greater extent than anticapsular IgG 

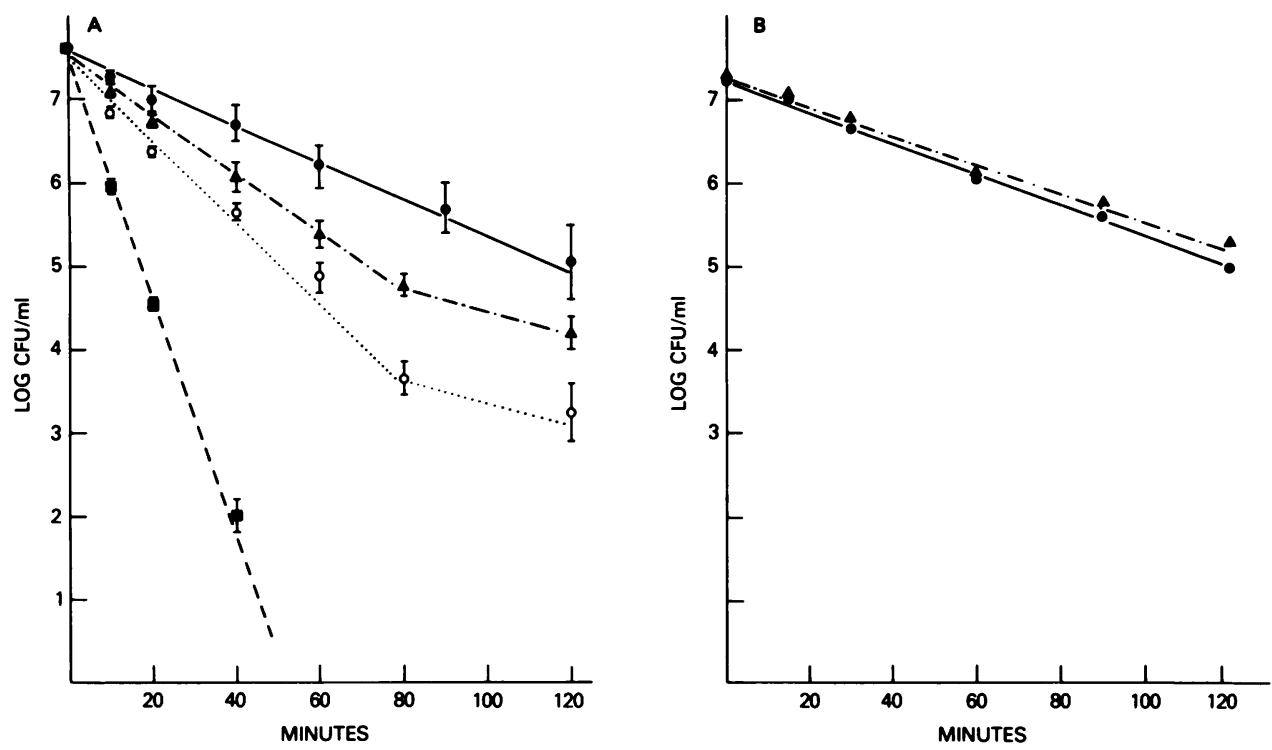

Figure 7 The clearance of IgM-sensitized Pn. The clearance in NIH-GP of type 7 Pn sensitized with $0(\bullet), 120(\triangle), 240(O)$, and $500(\square)$ molecules of IgM/CFU is compared in A. In B the clearance in C4D-GP of type 7 Pn sensitized with $0(0)$ and 1,025 (A) molecules of IgM/CFU is compared. In each case the number of CFU present in $1 \mathrm{ml}$ of blood is plotted vs. time since intravenous injection.

at equal inputs of antibody. Thus, the difference in opsonic activity between antibody to cell wall components and antibody to polysaccharide capsule was not a function of different abilities to activate complement.

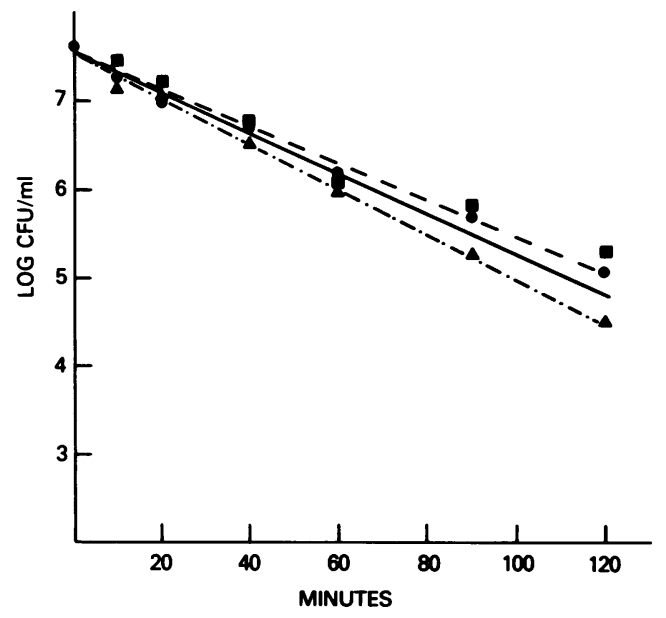

Figure 8 The clearance of anticell wall IgG-sensitized type $7 \mathrm{Pn}$ in normal nonimmune guinea pigs. The bloodstream clearances of type $7 \mathrm{Pn}$ sensitized with $0(0), 15,000(\Delta)$, and 44,000 (ש) IgG/CFU are compared by plotting CFU/ $\mathrm{ml}$ of blood vs. time since intravenous injection of the Pn. Pn sensitized with $1,600,3,200$, and 30,000 IgG/CFU also showed no difference in clearance rate from PBS-incubated Pn (data not shown).
Antibody-mediated C3 fixation to Pn. Next, we examined whether complement activation by the different antibody preparations led to equivalent amounts of complement deposition on the Pn. Because complement-mediated opsonization occurs primarily be-

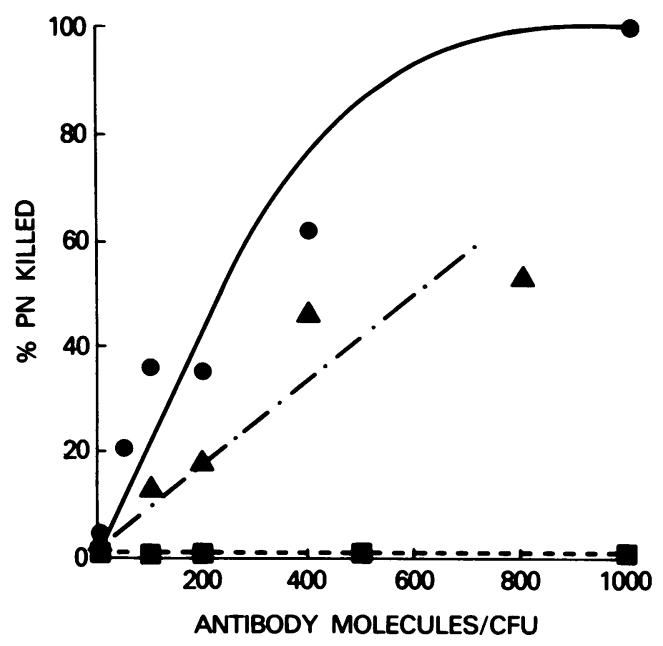

Figure 9 The effects of anticapsular and anticell wall antibody on in vitro phagocytosis of $\mathrm{Pn}$. The abilities of anticapsular IgG (O), anticapsular IgM ( $\Delta)$, and anticell wall IgG $(\square)$ to enhance serum-dependent pneumococcal killing are compared. There is a dose-dependent increase in killing mediated by anticapsular IgG and IgM. IgG anticell wall has no effect on phagocytosis of Pn by PMN. 


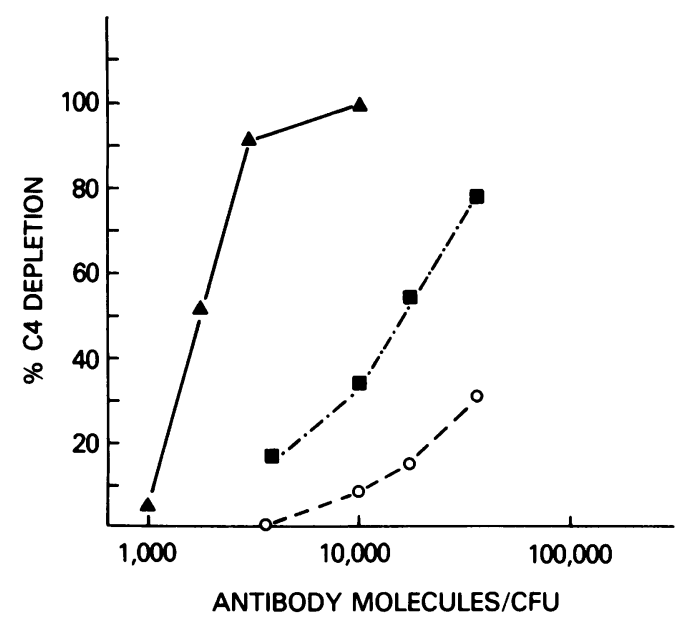

Figure 10 Serum C4 depletion by antibody-sensitized Pn. The effects of presensitization of Pn with various amounts of anticapsular IgM ( $\Delta)$, anticapsular IgG (O), and anticell wall IgG ( $\square$ ) on the ability of these Pn to deplete C4 from guinea pig serum are compared. For all three antibodies, C4 depletion increases with increasing levels of pneumococcal sensitization.

cause of the fixation of $\mathrm{C} 3 \mathrm{~b}$ to the bacterial surface (32), we examined the ability of IgM and IgG anticapsular antibody and of IgG anticell wall antibody to mediate the deposition of ${ }^{125} \mathrm{I}$-labeled C3b onto Pn. In the first set of experiments, $1 \%$ serum was used as the source of the C3 convertase, as it had been in the complement depletion studies. Radiolabeled C3 de-

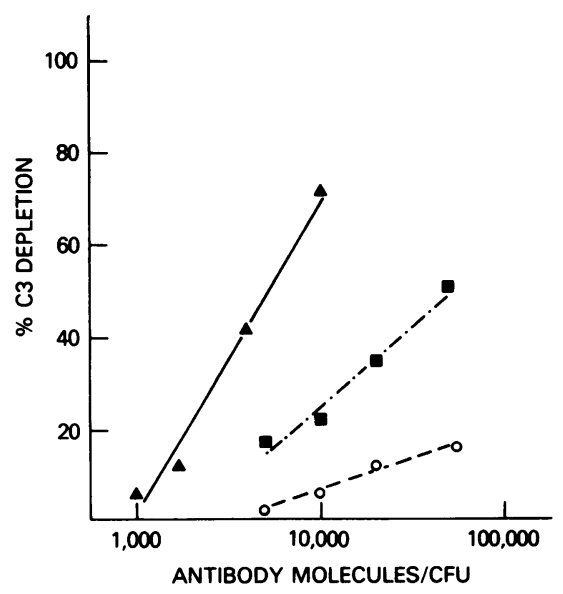

Figure 11 Serum C3 depletion by antibody-sensitized Pn. The effects of presensitization of Pn with increasing amounts of anticapsular IgM $(\Delta)$, anticapsular IgG $(O)$, and anticell wall IgG (ם) on the ability of these Pn to deplete C3 from GPS are compared. With all three antibodies, C3 depletion increases with increasing levels of pneumococcal sensitization. position on the $\mathrm{Pn}$ increased as the amount of antibody used to sensitize the Pn was increased for all three antibody preparations. As it had been in the depletion studies, anticapsular IgM was most efficient at the process of C3 deposition. Again, as in the depletion studies, anticell wall IgG was at least as efficient as anticapsular IgG in mediating C3 deposition on Pn (Fig. 12). To examine the ability of the isolated components of the classic pathway to cause C3 fixation, ${ }^{125} \mathrm{I}-\mathrm{C} 3 \mathrm{~b}$ uptake was examined when sensitized Pn were incubated sequentially with purified $\mathrm{Cl}, \mathrm{C} 4, \mathrm{C} 2$, and ${ }^{125} \mathrm{I}-$ C3. For all three types of antibody there was an antibody dose-dependent uptake of $\mathrm{C} 3$ onto the sensitized Pn, as had been the case in dilute GPS (data not shown).

Immune adherence. The interaction of $\mathrm{C} 3 \mathrm{~b}$ on antibody-sensitized $\mathrm{Pn}$ with the $\mathrm{C} 3 \mathrm{~b}$ receptor on human $E$ was examined via the ability of sensitized Pn to cause immune adherence (33). Pn were sensitized with 5,000 molecules of IgG anticell wall antibody, 5,000 molecules of IgG anticapsular antibody, or 1,000 molecules of IgM anticapsular antibody per bacterium. To exclude any contribution of nonantibody-mediated, alternative pathway-activated C3, C3 deposition was achieved by assembly of a classic pathway $\mathrm{C} 3$ convertase with purified $\mathrm{Cl}, \mathrm{C} 4, \mathrm{C} 2$, and $\mathrm{C} 3$. This led to the deposition of 1,200 molecules of $\mathrm{C} 3 / \mathrm{CFU}$ on the Pn sensitized with IgM, 1,100 molecules/CFU on those sensitized with anticell wall IgG, and $600 \mathrm{~mol}-$ ecules/CFU on Pn sensitized with IgG anticapsular antibody. When Pn were tested for immune adher-

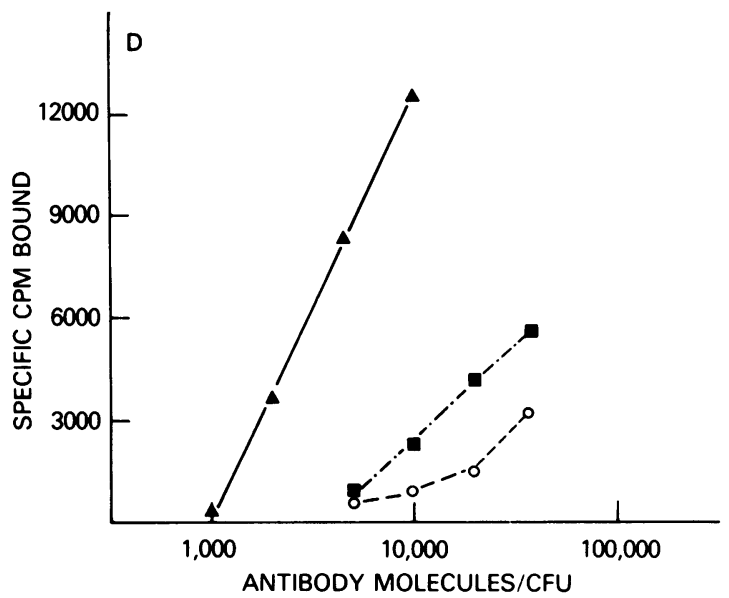

Figure 12 Serum-mediated fixation of C3 to antibody-sensitized Pn. The amount of ${ }^{125} \mathrm{I}-\mathrm{C} 3$ bound after serum incubation to $2.5 \times 10^{7} \mathrm{Pn}$ presensitized with increasing amounts of antibody is compared for anticapsular $\operatorname{IgM}(\Delta)$, anticapsular IgG $(O)$, and anticell wall IgG ( $\square)$. For all three antibodies, the amount of $\mathrm{C} 3$ bound by the Pn increases with increasing levels of antibody sensitization. 
ence, the IgM and IgG anticapsular antibody-sensitized cells gave a $4+$ reaction, whereas the bacteria sensitized with IgG anticell wall were immune adherence negative (Table II).

\section{DISCUSSION}

In this study we examined and compared the effects of purified anticapsular IgG and IgM with anticell wall IgG on the clearance of Pn from the bloodstream of nonimmune guinea pigs. Immunization is known to protect both experimental animals and humans from pneumococcal infection because of the development of type-specific antibody $(11,34)$, but the way in which antibody protects against in vivo challenge has been largely uninvestigated. The studies reported here suggest that opsonization of Pn with type-specific antibody, either IgG or IgM, requires the mediation of complement for in vivo efficacy. The evidence for this was provided by studies of the rates of clearance of intravenously injected, antibody-sensitized Pn in NIHGP, which have normal complement pathways; in C4D-GP, which can activate complement only via the alternative pathway; and in CVF-GP, which are markedly deficient in C3, the primary opsonin of the complement system (35). Even large amounts of IgM anticapsular antibody had no effect on clearance of Pn if activation of the classical pathway was blocked, as in C4D-GP. Although anticapsular IgG had some effect on the rate of pneumococcal clearance in C4DGP, its opsonic capability was markedly diminished compared with its effect in NIH-GP. Even this small effect of IgG in C4D-GP required complement activation via the alternative pathway, since all effect of IgG was abolished in CVF-GP. Thus, antibody-mediated classical pathway activation is essential for the expression of any opsonic effect of type-specific IgM and for the maximum effect of anticapsular IgG. The small but significant effect of IgG antibody in C4DGP provides some evidence that IgG but not IgM activates the alternative pathway. In its ability to enhance alternative pathway activation, anticapsular IgG is similar to a number of previously reported IgG antibodies $(36,37)$. When we examined the number of IgG or IgM molecules required to increase the clearance rate of $\mathrm{Pn}$ in NIH-GP, we found that $1,400 \mathrm{IgG}$ molecules/CFU and $120 \mathrm{IgM}$ molecules/CFU were sufficient. Since in these studies each $\mathrm{Pn}$ is capable of binding $\sim 150,000 \mathrm{IgG},<1 \%$ of the antibody-binding sites on the pneumococcal capsule needed to be occupied to achieve an opsonic effect. Levels of antibody sensitization that led to a more rapid bloodstream clearance also caused increased hepatic sequestration of Pn. These effects of IgG and IgM added in vitro are
TABLE II

Immune Adherence of Pn Sensitized with Opsonic and Nonopsonic Antibody

\begin{tabular}{crc}
\hline Antibody & C3/CFU & $\begin{array}{c}\text { Immune } \\
\text { adherence }\end{array}$ \\
\hline IgM: type 7 & 1,200 & $4+$ \\
IgG: type 7 & 600 & $4+$ \\
IgG: cell wall & 1,100 & - \\
\hline
\end{tabular}

Pn were sensitized with 1,000 molecules/CFU of IgM anticapsular antibody or 5,000 molecules/CFU of anticell wall IgG or anticapsular IgG, leading to the deposition of approximately equal numbers of C3 molecules/CFU. These antibody- and complement-sensitized Pn were then tested for their ability to bind to the human $\mathrm{E}$ C3b receptor by the immune adherence reaction.

similar to the changes in clearance and localization that occur after immunization of guinea pigs $(14,15$, $20,21)$. As is the case with these purified antibodies, the increased rates of clearance and increased hepatic localization that accompany immunization depend upon activation of complement. Thus, the beneficial effects of immunization on pneumococcal clearance could be reproduced with small amounts of type-specific antibody.

Several important conclusions about the role of anticapsular antibody can be made by a comparison of the bloodstream clearance of $\mathrm{Pn}$ with the clearance of guinea pig erythrocytes (GPE), which do not activate complement in the absence of antibody $(38,39)$. Optimal bloodstream clearance in both cases is complement dependent. IgM anticapsular polysaccharide and IgM antierythrocyte antibody opsonize their respective antigens via activation of the classic pathway. However, the ultimate fates of IgM-sensitized Pn and erythrocytes are very different. IgM-coated GPE are removed from the circulation only transiently, to return and circulate with a normal half-life. In contrast, IgM anticapsular antibody causes the rapid and definitive removal of Pn from the blood.

The effects of IgG antibody on the clearance of Pn and GPE differ in several ways. First, antierythrocyte IgG antibody does not interact with the alternative pathway of complement activation, but anticapsular IgG probably does. Second, Pn sensitized with anticapsular IgG do not interact significantly with the splenic IgG receptor, since their clearance is not enhanced in the absence of complement; this is unlike the clearance of IgG-coated E, which are sequestered by the spleen at a slow rate in CVF-GP. Finally, anticapsular IgG mediates hepatic clearance of Pn, whereas IgG-sensitized GPE are sequestered by the 
spleen, except at very high levels of antibody sensitization.

We have also characterized a rabbit IgG antipneumococcal antibody that reacts with pneumococcal cell walls, and we have shown that it does not enhance either the bloodstream clearance of $\mathrm{Pn}$ in vivo or the killing of Pn by PMN in vitro. In this respect it is clearly different from both the IgG and the IgM antipneumococcal antibodies with specificity for the polysaccharide capsule. Because it does not affect the ability of either PMN or the fixed macrophages of the reticuloendothelial system to ingest $\mathrm{Pn}$, we have called this anticell wall antibody nonopsonic.

In agreement with our findings, there are many studies in animals and humans that demonstrate that anticell wall antibodies are not opsonic (summarized in reference 3 ). Some investigators, however, have found antipneumococcal cell wall antibodies that confer protection in mice (40-42). This discrepancy may have been resolved by Briles et al. (43), who showed that monoclonal antiphosphorylcholine antibodies could protect mice against lethal infection by an encapsulated pneumococcus. Thus, the differences in opsonic effect between protective and nonprotective anticell wall antisera may relate to differences in the amounts of antiphosphorylcholine antibody they contain. Because the C-carbohydrate that contains the cell wall phosphorylcholine (44) is poorly immunogenic (45), there is likely to be little antiphosphorylcholine antibody in most anticell wall preparations.

Because the opsonic effect of rabbit anticapsular antibody in vivo, whether IgM or IgG, depends on its ability to fix complement, we tested the hypothesis that the difference between opsonic and nonopsonic antibodies lies in their ability to activate complement. However, the experiments demonstrated that IgG anticell wall antibody was slightly more efficient than IgG anticapsular antibody, both in its ability to activate complement, as judged by the depletion of $\mathrm{C} 4$ and $\mathrm{C} 3$ in serum, and in its ability to deposit radiolabeled guinea pig C3 onto the pneumococcal surface. This was not an artifact of the use of dilute GPS, since anticell wall IgG also mediated C3 deposition on Pn as efficiently as anticapsular IgG in much more concentrated $(10 \%)$ serum. Hence, the difference in opsonic effect between the anticapsular and anticell wall antibodies is not explained by differences in their ability to fix complement to Pn. As shown by the experiments with purified components of the classic pathway, anticapsular IgG was no better at mediating the formation of a classical pathway $\mathrm{C} 3$ convertase than anticell wall IgG. IgG antibodies may affect the rate of alternative pathway activation (46) and, theoretically, anticapsular IgG might lead to greater alternative pathway-mediated amplification of C3 deposition than anticell wall IgG. However, the anticapsular IgG was no better at mediating complement activation in guinea pig serum when both the classic and alternative pathways were present than the anticell wall IgG.

Although the opsonic anticapsular antibodies were totally dependent on complement activation to achieve an in vivo effect, the difference between opsonic and nonopsonic antibodies in their effect on phagocytosis could not be explained by differences in their ability to activate complement or fix C3 to the Pn. Therefore, we hypothesized that complement fixed to the surface of Pn by anticell wall IgG was less readily available to the phagocytic cell complement receptors. The results of experiments performed to test the ability of the different antibodies to mediate immune adherence, a phenomenon dependent on the ability of particle-bound $\mathrm{C} 3 \mathrm{~b}$ to interact with $\mathrm{C} 3 \mathrm{~b}$ receptors on human E $(33,47)$ support this idea. At levels of sensitization that led to the deposition of approximately equal numbers of C3b molecules, Pn sensitized with anticapsular antibodies, whether IgG or IgM, were able to cause immune adherence, whereas those sensitized with the anticell wall IgG were not. Thus, the different cellular locations of the antibodies led to deposition of C3b in locations on the Pn that varied in their ability to interact with the $\mathrm{E} \mathrm{C} 3 \mathrm{~b}$ receptor. It has been shown in both chemical (48) and electron microscope studies (49) that the alternative pathway of complement causes C $3 \mathrm{~b}$ deposition on the cell walls of encapsulated organisms. Thus, the important physiologic difference between cell wall-bound and capsular C3b demonstrated in these experiments provides an explanation for the requirement for specific anticapsular antibody in host defense against encapsulated organisms.

These studies on pneumococcal bacteremia suggest a central role for complement activation and for the precise site of $\mathrm{C} 3 \mathrm{~b}$ fixation in the protective effects of anticapsular antibody in experimental pneumococcal bacteremia. However, it has been observed that the antipneumococcal antibodies of some species, including human, will not activate complement (50). This conclusion, derived largely from the work of Horsfall and Goodner in the 1930s (51-53), is based on data from experiments employing purified capsular polysaccharide, unfractionated immune serum, and insensitive methods to detect complement consumption. Recent studies in our own laboratory, however, using whole organisms and more sensitive techniques for detecting complement fixation, have demonstrated that under these circumstances human antipneumococcal antibodies can, indeed, activate and fix complement (54). Thus, it is probable that complement 
plays an equally critical role in the mediation of the protective effect of human anticapsular antibody as we have shown in the experimental model.

\section{REFERENCES}

1. Bezançon, F., and V. Griffon. 1897. Pouvoir agglutinatif du sérum dans les infections experimentales et humaines á pneumocoques. I. Compt. Rend. Soc. Biol. 49: 551579.

2. Avery, O. T., and M. Heidelberger. 1923. Immunological relationships of cell constituents of pneumococcus. J. Exp. Med. 38: 81-102.

3. Heffron, R. 1979. Pneumonia, with Special Reference to Pneumococcus Labor Pneumonia. Harvard University Press, Cambridge, Massachusetts. 805-921.

4. Finland, M., J. M. Ruegsegger, and L. D. Felton. 1935. Should heterophile antibodies be used in the treatment of pneumococcic pneumonia? J. Am. Med. Assoc. 105: 1180-1182.

5. Reimann, H. A. 1926. Serological relationships of type specific and degraded pneumococci. J. Exp. Med. 43: 107-121.

6. Tillett, W. S. 1928. Active and passive immunity to pneumococcus infection induced in rabbits by immunization with pneumococci. J. Exp. Med. 48: 791-804.

7. Thompson, H. C. W., and I. S. Snyder. 1971. Protection against pneumococcal infection with a ribosomal preparation. Infect. Immun. 3: 16-23.

8. Enders, J. F., C-J. Wu, and M. F. Shaffer. 1936. Studies on natural immunity to pneumococcus type III. IV. Observations on a non-type specific humoral factor involved in resistance to pneumococcus type III. J. Exp. Med. 64: 425-438.

9. Wright, H. D. 1927. Experimental pneumococcal septicemia and antipneumococcal immunity. J. Pathol. Bacteriol. 30: 185-252.

10. Enders, J. F., M. F. Shaffer, and C-J. Wu. 1936. Studies on natural immunity to pneumococcus type III. III. Correlation of the behavior in vivo of pneumococci type III varying in their virulence for rabbits with certain differences observed in vitro. J. Exp. Med. 64: 307-331.

11. Wright, H. D. 1927. Experimental pneumococcal septicemia and antipneumococcal immunity. J. Pathol. Bacteriol. 30: 185-252.

12. Horwitz, M. A., and S. C. Silverstein. 1980. Influence of Escherichia Coli capsule on complement fixation and on phagocytosis and killing by human phagocytes. $J$. Clin. Invest. 65: 82-94.

13. Ehlenberger, A. G., and V. Nussenzweig. 1977. The role of membrane receptors for C3b and C3d in phagocytosis. J. Exp. Med. 145: 357-371.

14. Hosea, S. W., E. J. Brown, and M. M. Frank. 1980. The critical role of complement in experimental pneumococcal bacteremia. J. Infect. Dis. 142: 903-909.

15. Brown, E. J., S. W. Hosea, and M. M. Frank. 1981. The role of the spleen in experimental pneumococcal bacteremia. J. Clin. Invest. 67: 975-982.

16. Gaither, T. A., C. H. Hammer, and M. M. Frank. 1979. Studies of the molecular mechanisms of inactivation and a simplified assay of $\beta 1 \mathrm{H}$ and the C3b inactivator. $J$. Immunol. 123: 1195-1204.

17. White, B. 1979. The Biology of the Pneumococcus. Harvard University Press, Cambridge, Massachusetts. 53.
18. Tomasz, A. 1964. Studies on the competence of genetic transformation in Diplococcus pneumoniae using a synthetic medium. Bacteriol. Proc. 64: 29. (Abstr.).

19. Ellman, L., I. Green, and M. M. Frank. 1970. Genetically controlled total deficiency of the fourth component of complement in the guinea pig. Science (Wash., D. C.). 170: 74-75.

20. Brown, E. J., S. W. Hosea, and M. M. Frank. 1981. The role of complement in localization of pneumococci in the splanchnic reticuloendothelial system during experimental pneumococcal bacteremia. J. Immunol. 126: 2230-2235.

21. White, B. 1979. The Biology of the Pneumococcus. Harvard University Press, Cambridge, Massachusetts. 633.

22. Hosea, S. W., E. J. Brown, C. H. Hammer, and M. M. Frank. 1980. The role of complement in a model of adult respiratory distress syndrome. J. Clin. Invest. 66: 375382.

23. Fujiwara, M. 1967. The Forssman antigen of pneumococcus. Jpn. J. Exp. Med. 37: 581-592.

24. Böyum, A. 1968. Isolation of mononuclear cells and granulocytes from human peripheral blood. Scand. J. Clin. Lab. Invest. 21(Suppl. 97): 77-89.

25. Hosea, S. W., C. G. Burch, E. J. Brown, R. A. Berg, and M. M. Frank. 1981. Impaired immune response of splenectomized patients to the polyvalent pneumococcal vaccine. Lancet. 1: 804-807.

26. Hammer, C. H., G. H. Wirtz, L. Renfer, H. D. Gresham, and B. F. Tack. 1981. Large scale isolation of functionally active components of the human complement system. J. Biol. Chem 256: 3995-4006.

27. Steinbuck, M., and R. Audran. 1969. The isolation of IgG from mammalian sera with the aid of caprylic acid. Arch. Biochem. Biophys. 134: 279-284.

28. March, S. C., I. Parikh, and P. Cuatrecasas. 1973. A simplified method for cyanogen bromide activation of agarose for affinity chromatography. Anal. Biochem. 60: 149-152.

29. Maizel, J. V., Jr. 1971. Polyacrylamide gel electrophoresis of viral proteins. In Methods in Virology. E. Maramorosch and H. Koprowski, editors. Academic Press, Inc., New York. 179-246.

30. Gaither, T. A., and M. M. Frank. 1979. Complement. In Clinical Diagnosis and Management by Laboratory Methods. J. B. Henry, editor. W. B. Saunders Co., Philadelphia. 1245-1262.

31. White, B. 1979. The Biology of the Pneumococcus. Harvard University Press, Cambridge, Mass. 323-354.

32. Gigli, I., and R. A. Nelson. 1968. Complement dependent immune phagocytosis. I. Requirements for $\mathrm{Cl}, \mathrm{C4}$, C2, C3. Exp. Cell Res. 51: 45-67.

33. Nelson, R. A. 1953. The immune adherence phenomenon. Science (Wash., D. C.). 118: 733-737.

34. MacLeod, C. M., R. G. Hodges, M. Heidelberger, and W. G. Bernhard. 1945. Prevention of pneumococcal pneumonia by immunization with specific capsular polysaccharides. J. Exp. Med. 82: 445-465.

35. Johnston, R. B., Jr., M. R. Klemperer, C. A. Alper, and F. S. Rosen. 1969. The enhancement of bacterial phagocytes by serum: the role of complement components and two cofactors. J. Exp. Med. 129: 1275-1290.

36. Schenkein, H. A., and S. Ruddy. 1981. The role of immunoglobulins in alternative complement pathway activation by zymosan. I. Human IgG with specificity 
for zymosan enhances alternative pathway activation by zymosan. J. Immunol. 126: 7-10.

37. Winkelstein, J. A., and H. S. Shin. 1974. The role of immunoglobulin in the interaction of pneumococci and the properdin pathway: evidence for its specificity and lack of requirement for the Fc portion of the molecule. J. Immunol. 112: 1635-1642.

38. Schreiber, A. D., and M. M. Frank. 1972. Role of antibody and complement in the immune clearance and destruction of erythrocytes. I. In vivo effects of IgG and IgM complement fixing sites. J. Clin. Invest. 51: 575582.

39. Schreiber, A. D., and M. M. Frank. 1972. The role of antibody and complement in the immune clearance and destruction of erythrocytes. II. Molecular nature of IgG and IgM complement fixing sites and effects of their interaction with serum. J. Clin. Invest. 51: 583-590.

40. Au, C. C., and T. K. Eisenstein. 1981. Nature of the cross-protective antigen in subcellular vaccines of Streptococcus pneumoniae. Infect. Immun. 31: 160-168.

41. Thompson, H. C. W., and T. K. Eisenstein. 1976. Biological properties of an immunogenic pneumococcal subcellular preparation. Infect. Immun. 13: 750-757.

42. Au, C. C., and T. K. Eisenstein. 1981. Evaluation of the role of the pneumococcal Forssman antigen ( $F$-polysaccharide) in the cross-serotype protection induced by pneumococcal subcellular preparations. Infect. Immun. 31: 169-173.

43. Briles, D. E., M. Nahm, K. Schroer, J. Daire, P. Baker, J. Kearney, and R. Barletta. 1981. Antiphosphocholine antibodies found in normal mouse serum are protective against intravenous infection with type 3 Streptococcus pneumoniae. J. Exp. Med. 153: 694-705.

44. Volanakis, J. E., and M. D. Kaplan. 1971. Specificity of C-reactive protein for choline phosphate residues of pneumococcal C-polysaccharide. Proc. Soc. Exp. Biol. Med. 136: 612-616.

45. Tillett, W. S., W. F. Goebel, and O. T. Avery. 1930.
Chemical and immunological properties of a species specific carbohydrate of pneumococci. J. Exp. Med. 52: 895-916.

46. Winkelstein, J. A., and H. S. Shin. 1974. The role of immunoglobulin in the interaction of pneumococci and the properdin pathway: evidence for its specificity and lack of requirement for the Fc portion of the molecule. J. Immunol. 112: 1635-1642.

47. Nelson, D. S. 1963. Immune adherence. Adv. Immunol. 3: $131-180$.

48. Winkelstein, J. A., A. S. Abramovitz, and A. Tomasz. 1980. Activation of C3 via the alternative pathway results in fixation of $\mathrm{C} 3 \mathrm{~b}$ to the pneumococcal cell wall. J. Immunol. 124: 2502-2506.

49. Wilkinson, B. J., S. P. Sisson, Y. Kim, and P. K. Peterson. 1979. Localization of the third component of complement on the cell wall of encapsulated Staphylococcus aurens. II. Implications for the mechanism of resistance to phagocytosis. Infect. Immun. 26: 1159-1163.

50. Austrian, R. 1975. Random gleanings from a life with the pneumococcus. J. Infect. Dis. 131: 474-484.

51. Goodner, K., and F. L. Horsfall. 1936. The complement fixation reaction with pneumococcus capsular polysaccharide. J. Exp. Med. 64: 201-216.

52. Horsfall, F. L., and K. Goodner. 1935. Lipids and immunological reactions. I. The relation of phospholipins to the type specific reactions of antipneumococcus horse and rabbit sera. J. Exp. Med. 62: 485-503.

53. Horsfall, F. L., and K. Goodner. 1936. Lipids and immunological reactions. II. Further experiments on the relation of lipids to the type specific reactions of antipneumococcus sera. J. Immunol. 31: 135-140.

54. Hosea, S. W., C. G. Burch, E. J. Brown, W. O. Fletcher, C. H. Hammer, and M. M. Frank. 1981. Relative contributions of antibody and complement in opsonization of the pneumococcus after immunization with the polyvalent pneumococcal vaccine. Clin. Res. 29: 387A. (Abstr.). 